\title{
Study on Employment Intention of Nursing Students and Practice Teaching in Community Nursing
}

\author{
Xiangyan Feng ${ }^{1, a}$ and Xiaona Jin $^{2, b^{*}}$ \\ ${ }^{1}$ Xi'an peihua University, Xi'an, Shaanxi, China; Post:710125 \\ ${ }^{2}$ Xi'an International University, Xi'an, Shaanxi, China; Post:710077 \\ a24138388@qq.com, binxiaonamv@163.com
}

\section{Keywords: Nursing students; Community nursing; Employment intention; Practice teaching}

\begin{abstract}
Goal] Understand community employment intentions of current nursing students in a private medical school in Xi'an and provide reference for community nursing education. [Method] Design survey questionnaire about the employment intentions of community nursing students. A cluster sampling survey was conducted on 456 nursing students in a private medical school in Xi'an and interviews were conducted with nursing students. [Result] There were significant differences in employ intentions for nursing students with different education levels $(p>0.01)$. There were $75.91 \%$ of the college graduate students, $60.47 \%$ of the undergraduate students and $59.09 \%$ of "top-up" students would like to be engaged in community nursing. Undergraduate nursing students are willing to be engaged in community nursing work due to the large degree of freedom of work and the space for development and are not willing to be engaged in community nursing work due to the low benefits and the small contact area; College graduate nursing students are willing to be engaged in community nursing work due to the working stability and small pressure and are not willing to be engaged in community nursing work due to the poor working environment. [Result] The limitations of understanding of the community is the school's training. It is necessary to train large quantities of high-quality community nursing personnel in order to strengthen the school education. In particular, it is important to strengthen nursing students community nurse practice education, to improve their awareness and to carry out education targeted at different levels of nursing students so as to correct the concept of career choice and broaden employment opportunities.
\end{abstract}

According to Healthy China 2030 plan, we will adjust and optimize the professional structure of medical education that adapts to the development of the health service industry and increase the training of healthy personnel, such as pensioners, rehabilitation therapists as well as counselors.

Guiding Opinions on Guiding the Transformation of Ordinary Colleges and Universities to Applied Type in Some Localities issued by Ministry of Education, National Development and Reform Commission, Ministry of Finance points out that colleges and universities all over the country should proceed from the overall situation of adapting to and leading the new normal of economic development and driving the development of service innovation and promote the transformation and development of some ordinary undergraduate colleges with the spirit of reform and innovation.

We will continue to improve the policy system for promoting transformation and development, and promote reforms in the fields of discipline professional setting, the mode of personnel training as well as other key areas. So that the educational goal of transitional high schools will be more in line with the needs of the society and the orientation in applied colleges and universities.In the context of the rising enrollment of higher education and the difficult employment of college graduates, employment for grass-roots and community has become an important direction for graduates for local colleges and universities ${ }^{[1]}$. Due to the professional advantage, ordinary undergraduate nursing students own relatively high position, so they have higher expectations of their career and are more willing to work in big hospital of big city. There are only a small number of them who will choose to be engaged in primary health care services of communities ${ }^{[2]}$. In this study, we investigated the willingness of undergraduate and specialist nursing students in a community-owned medical college in Xi'an to analyze their influence factors and provide reference for community nursing education and employment guidance. 


\section{Objects and Methods}

Objects. The object of this study was a cluster sampling method. A total of 456 undergraduates, college graduates and "top-up" students from a private medical school in Xi'an were enrolled in this study. Among them, 16 were males and 440 were females and all of them had Community Nursing theoretical courses, and had their internship in hospital. Through the signing of informed consent, they voluntarily participated in the study. Exclusion criteria: did not learn Community Nursing course; did not want to participate in this study; nursing students who have graduated.

\section{Methods}

Research tool. On the basis of the questionnaire used by Sun Xiaojia in investigating and researching the occupational attractiveness of community nursing work, a questionnaire which is suitable for nursing students in private colleges and universities was designed with reference to interdisciplinary research methods such as nursing, humanities, sociology and public health. The questionnaire has good reliability and validity. Experts on community nursing and career guidance were invited to assess whether the content of the questionnaire and the form of topics are appropriate, according to which, the questionnaire was notified. The pre-investigation was done to 20 undergraduate and college graduate students. The questionnaire included four aspects: the basic situation of nursing students, the level of community nursing awareness, the attitude of community employment intentions, the understanding of industry prospects.

The method of data collection was informed by the investigators of the purpose of the study. The questionnaires were issued after the informed consent was signed. The requirements and precautions for filling in the questionnaires were uniformly described and the questionnaires were collected on the spot. Both the recovery rate and the efficiency rate of the questionnaires reached $100 \%$.

All collected questionnaires were numbered in a unified way and entered into the system by two persons. SPSS20.0 software was used for statistical analysis of the data.

\section{Result}

Different intentions of community nursing employment of the nursing students with different education levels of a private medical school in Xi'an.

The differences of the intentions of community nursing employment of the nursing students with different education levels ( $p>0.01$ ) were statistically significant. Among them, the intentions of community nursing employment of college graduate students are higher than that of undergraduate students, that of enrollment undergraduate are higher than that of "top-up" students. This is consistent with the results of Tang Sai et al. ${ }^{[4]}$. See Table 1 for details.

Table 1 Differences of the intentions of community nursing employment of the nursing students with different education levels [n(\%)]

\begin{tabular}{|l|l|l|l|l|}
\hline Education & Number of people & Willing & Can consider & Not willing \\
\hline College graduates & 137 & $104(75.91)$ & $23(16.79)$ & $10(7.30)$ \\
\hline Undergraduates & 253 & $153(60.47)$ & $69(27.27)$ & $31(12.25)$ \\
\hline "Top-up" students & 66 & $39(59.09)$ & $12(18.18)$ & $15(22.73)$ \\
\hline Note: X2 = P<0.01 \\
\hline
\end{tabular}

Influential factors of community employment intentions of nursing students in a private medical college in Xi'an. In the private medical college in Xi'an, undergraduate nursing students are willing to be engaged in community nursing work due to the large degree of freedom of work and the space for development and are not willing to be engaged in community nursing work due to the low benefits; College graduate nursing students are willing to be engaged in community nursing work due to the working stability and small pressure and are not willing to be engaged in community nursing work due to the poor working environment. See Table 2 for details. 
Table 2 Influencing Factors on Community Employment Intentions of Nursing Students with Different Education Levels [n(\%)]

\begin{tabular}{|l|l|l|l|l|}
\hline Items & Undergraduates & $\begin{array}{l}\text { College } \\
\text { graduates }\end{array}$ & X2 & P \\
\hline Nursing students are willing to work in the community & 71.74 & $<0.01$ \\
\hline $\begin{array}{l}\text { High working stability and small working } \\
\text { pressure }\end{array}$ & $56(17.56)$ & $78(56.93)$ & & \\
\hline High degree of freedom of work & $84(26.33)$ & $20(14.59)$ & & \\
\hline Challenging work & $69(21.63)$ & $16(11.68)$ & & \\
\hline Great room for development & $110(34.48)$ & $23(16.79)$ & & \\
\hline Nursing students are not willing to work in the community & & 30.76 & $<0.01$ \\
\hline Low benefits & $101(31.67)$ & $23(16.79)$ & \\
\hline Poor working environment & $73(22.89)$ & $52(37.96)$ & & \\
\hline Low social acceptance & $70(21.94)$ & $48(35.04)$ & & \\
\hline $\begin{array}{l}\text { Relatively unfamiliar with community nursing } \\
\text { work }\end{array}$ & $75(23.51)$ & $14(10.21)$ & & \\
\hline
\end{tabular}

\section{Discussion}

Analysis of Intentions to be Engaged in Community Nursing Work of Students With Different education levels. This study selected undergraduate and college graduate nursing students from a private medical school in Xi'an as the research objects. Among them, the difference of the overall intentions in community nursing employment of students with different education levels statistical significance ( $\mathrm{p}<0.01$ ), which is consistent with the overall intentions in community nursing employment of students with different education levels in a single institution ${ }^{[5]}$. Undergraduate and college graduate nursing students have different admission scores, starting point of study, learning experience and learning objectives, leading to their different career perspectives, graduation intentions and employment destination, etc ${ }^{[6]}$. Undergraduate and college graduate students have totally different academic years, curriculum, training objectives and career guidance. Therefore, the values and employment outlook which have formed during their school years are also different. Nursing "top-up" students are college graduates admitted to undergraduates with the academic structure for two years. They also receive bachelor diploma and bachelor degree certificate. Nursing "top-up" students have a deeper understanding of nursing and a more objective view on employment after graduation and employment choice. When faced with the choice again, nursing "top-up" students will be more clear with their own circumstances and more targeted to their employment orientation. The intentions of community nursing employment of nursing "top-up" students are generally lower than that of undergraduate nursing students. At the same time, nursing students have different employment positioning. Undergraduate nursing students have better employment conditions and the one-time employment rate is relatively high. The current status of community nursing in China which are low benefits, poor working environment, low social acceptance, unfamiliar with community nursing and other factors will affect their choice. When choosing a job, their intentions to work in community are relative minimum. After graduation, college graduate nursing students will face two choices which are continue the undergraduate course or seek a job. Both of the two choices have the high intentions. The intentions to choose a job are relatively low. The positioning of the first employment is more in line with their own development characteristics, so even the community nursing and the primary nursing of our country of all aspects are not satisfactory, they still choose community work.

The Status Quo of Community Nursing Work has Become the Resistance of Nursing Students to Choose Community Nursing Work. The intentions of community nursing employment of both the undergraduate and college graduate nursing students are relatively low, 
which is not only attributed to nursing students themselves and has related to the current situation of community nursing of our country. At present, the community nursing of China is in the stage of development, which is imbalanced in all aspects. There are also regional differences that the economically developed areas are developing more rapidly than the economically backward areas are. The eastern coastal cities are developing more rapidly than the inland cities in the west are ${ }^{[7]}$. In addition, the survey of Sun Xiaojia ${ }^{[3]}$ also shows that nursing students are not willing to choose community nursing work because of the large working load, complex working content, poor welfare, not perfect system, low social recognition, not conducive to personal development space and the realization of value. Therefore, the current development of community nursing in our country is not optimistic, mainly because its employment attraction is not enough to allow more nursing talents to choose it. Therefore, it is necessary for government departments to strengthen their policies on the community.

Strengthen the Practice Teaching of Community Nursing of Nursing Students During Teaching Process. From the perspective of the long-term development of community nursing, it is necessary to strengthen school education in order to cultivate mass and high quality community nurses $^{[8]}$. Community nursing education in China started relatively late. According to the survey, at present, most medical colleges and universities have set up community nursing courses. However, in the actual teaching process, it has always been more emphasis on clinical nursing education, which neglects community nursing education. Therefore, there is still a big gap and difference between domestic community nursing education and foreign nursing education, which lags far behind the actual nursing needs in our country. In this survey, there were $23.51 \%$ of undergraduates and $10.21 \%$ of college graduate nursing students who were unfamiliar with the community nursing work. Therefore, in the process of the transformation to application-oriented colleges, we should pay attention to the discipline construction of community nursing and carry out the necessary curriculum reform. In the teaching Community Nursing, introduce the advanced working modes and successes of community nursing experience at home and abroad, vigorously promote the national new medical reform to strengthen community health service system construction to enable nursing students to recognize that the domestic community nursing started late, but the room for development is large; continue to strengthen the creation and innovation of the community nursing teaching content and teaching methods, and stimulate nursing students' interests in learning to guide students with a positive attitude to face the community nursing work; continue to increase the proportion of community nursing practice and strengthen nursing students nursing skills training.

Community nurses have a wide range of working contents. Therefore, "community nurses are full-service nurses" with comprehensive nursing skills. Community nurses work in depth and have a high degree of autonomy. They should deal with emergencies and solve problems independently ${ }^{[9]}$. To deepen the reform of community nursing course system, private colleges should develop more mature community health service centers and sites in the area as practical bases according to their own teaching conditions and students 'conditions, and guide nursing students to practice in-person and stimulate nursing students' learning interests and motivation, enhance the autonomy of nurse students and correctly handle public health emergencies.

\section{Conclusion}

At present, college nursing graduates have shown the tendency of developing relative surplus, uneven distribution of talents and difficulties in employment, which is especially evidence among graduates of private colleges and universities. In sharp contrast, many community health service institutions cannot recruit highly educated nurses. The percentage of graduates who actually enter the community is still low. Therefore, it is necessary to guide part of nursing students in private colleges into community employment so as to make the large number of higher nursing talents who have difficulties in employment in major hospitals achieve better connection with the rapidly developing community health institutions, in order to promote the better development of primary nursing institutions. These have become major issues to be noticed by college teachers, especially career guidance teachers. Strengthen the employment education of nursing students so that nursing 
students can recognize the employment situation, take the initiative to obtain employment information, decide the correct positioning according to their own conditions and combine the individual's self-worth with social employment needs. Pay particular attention to guide college graduate nursing students to the community employment ${ }^{[10] .}$

This study is based on the survey and analysis of the intentions of community nursing employment of nursing students in a private college in Xi'an. However, the sample size is small, which cannot fully reflect the actual situation of all nursing students. The influence factors are limited to the investigation objects. In the future research, the level of survey division shall be expanded, so that the survey results will be more objective and comprehensive. In a word, the nursing cognition of nursing students with different levels is not enough, and the intention of community nursing employment is related to community nursing education. Therefore, nursing educators shall take corresponding measures to improve the nursing professional identity of nursing students with different levels and carry out professional and scientific career guidance.

\section{References}

[1] Rong Peng, Hong Xie and Xiaohong Jiang. Local college medical undergraduate employment ideal and reality [J]. China Higher Medical Education, 2011, (10): 31-32.

[2] Lili Lu, Tao Sujun and Tingting Zheng, et al. Investigation and Analysis of Nursing Internship Intentions of Nursing Students in Zhejiang Province [J]. Chinese Journal of Practical Nursing, 2008,24 (20): 66-68.

[3] Xiaojia Sun. Investigation on occupational attractiveness of nurses and clinical nurses in community nursing [J]. Nursing Research, 2010, (18): 1613-1614.

[4] Sai Tang, Chen Lei and Yang Juan. A medical college nursing students community nursing employment survey [J]. China Health Industry, 2016,13 (19): 190-192.

[5] Hui Wang. Comparison of Community nursing employment intentions of nursing of nursing students with different education levels [J] .Journal of Binzhou Medical College, 2013,36 (05): 363-365.

[6] Hui Wang. Community nursing employment intentions of nursing and related factors of nursing students with different education levels [J]. Journal of Community Medicine, 2015,13 (01): 25-28.

[7] Juan Feng and Fenfang Luo. Internship Nursing Students Community Care Occupational Recognition Attitude [J]. Nursing Journal, 2010,17 (4B): 72-73.

[8] Lingjuan Cui, Ruizhen Yang and Peipei Chen, et al. Demand for community nursing talent in China [J]. China Primary Health Care, 2012.26 (6): 25-26

[9] Guixiang Sun, Haixia Jiang and Xiuyin Gao. Existing problems and suggestions in the training of nursing education of Luzhajun community[J]. Chinese General Practice, 2007,10 (9): $742-743$.

[10] Jiaming Bao, Wei Fu and Hu Binchun. Analysis and countermeasures of status quo of the community nursing human resource management [J]. Chinese Journal of Practical Nursing, 2004, 20 (11): 61-62. 